\title{
Two-Stage Treatment of a Large Pelvic Cystic Pseudotumor in a Metal-On-Metal Total Hip Arthroplasty
}

\author{
Umberto Cottino $^{1}$ Federico Dettoni ${ }^{1}$ Salvatore Risitano ${ }^{1}$ Antonio Marmotti ${ }^{1}$ Roberto Rossi ${ }^{1,2}$ \\ ${ }^{1}$ Department of Orthopaedics and Traumatology, Ospedale \\ Mauriziano Umberto I, Turin, Italy \\ 2 Department of Orthopedics and Traumatology, University of Turin, \\ Turin, Italy \\ Address for correspondence Umberto Cottino, MD, Ospedale \\ Mauriziano Umberto I, Largo Turati 62, 10128 Turin, Italy \\ (e-mail: umberto.cottino@gmail.com).
}

Joints 2017;5:121-124.

\begin{abstract}
Keywords

- Metal-On-Metal

- pseudotumor

- synovial cyst

- total hip arthroplasty

- revision surgery

- two-stage technique

The authors report a case of a huge cystic pseudotumor, surrounding a failed metal-onmetal total hip arthroplasty (THA). The cyst surrounded the hip anteriorly, occupied part of the anterior portion of the thigh, and extended to the anterolateral aspect of the abdomen. The case was treated by a two-stage procedure. The first stage consisted of a percutaneous drainage of the fluid content of the cyst $(\sim 1,200 \mathrm{~mL})$. This procedure reduced the risk of tearing the cyst capsule spreading the liquid in the tissues surrounding the THA, and in the abdomen. Thanks to this simple procedure, the second stage treatment consisted of a relatively usual THA revision. The patient recovered completely from the treatment and returned to pain-free full activities of daily living.
\end{abstract}

\section{Introduction}

Pseudotumor is a complication described after metal-onmetal (MoM) and metal-on-polyethylene total hip arthroplasty (THA). The incidence is reported around $1.8 \%{ }^{1}$ The definition of pseudotumor is still controversial. The term pseudotumor is used to describe soft-tissues lesions with different morphologies, as granulomatous ${ }^{2,3}$ or sarcoidlike solid lesions, ${ }^{4}$ or cystic lesions with fluid content. ${ }^{5}$ The symptoms may vary from absence of symptoms to pain associated with rashes, instability, nerve palsy, ${ }^{6}$ and prosthetic loosening with osteolysis. ${ }^{7}$ These lesions are due to biological reactions consistent with hypersensitivity reactions to metal ions released for abrasive wear of the prosthesis. This immunological response is known as aseptic lymphocyte dominated vasculitis associated lesion. ${ }^{8}$ In most of the cases, a pseudotumor requires a surgical excision and complicates revision procedures. Removing these lesions can be hazardous: a complete excision may jeopardize bones, neurovascular structures, and tendons. Damaging a cystic lesion can pour out the liquid content in the perilesional structures, including the peritoneum. ${ }^{9}$ Pseudotumors are also associated with significantly elevated serum and articu- lar cobalt and chromium ion levels. ${ }^{1}$ These levels are directly proportional to time from onset of symptoms to revision; ${ }^{9}$ therefore, early treatment is required.

We present a case of a patient with a huge pelvic cystic pseudotumor treated with a two-stage approach.

\section{Case Report}

The patient (R.O., a 72-year-old lady, $168 \mathrm{~cm}, 57 \mathrm{~kg}$ ), underwent a right THA in 1999, with a PTP cup and a PPF stem (Stratec Biomedical AG, Birkenfeld, Germany) with a MoM coupling. The postoperative outcome was good and completely pain-free.

In February 2014, 15 years after the surgery, the patient experienced a sudden pain in the right hip without any trauma. She was referred to our department for functional weakness and pain in the groin, greater trochanter, and gluteus regions; she was able to walk only after supported by two crutches. Passive mobilization of the hip caused pain and produced articular crepitus. An abdominal mass was palpable in the right hypochondrium.

The implant showed signs of liner breakage/dislocation with great osteolysis at the top of the cup. On magnetic
DOI https://doi.org/ 10.1055/s-0037-1603676. ISSN 2282-4324.
Copyright @ 2017 Georg Thieme Verlag KG Stuttgart · New York
License terms

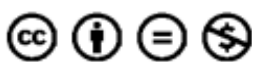




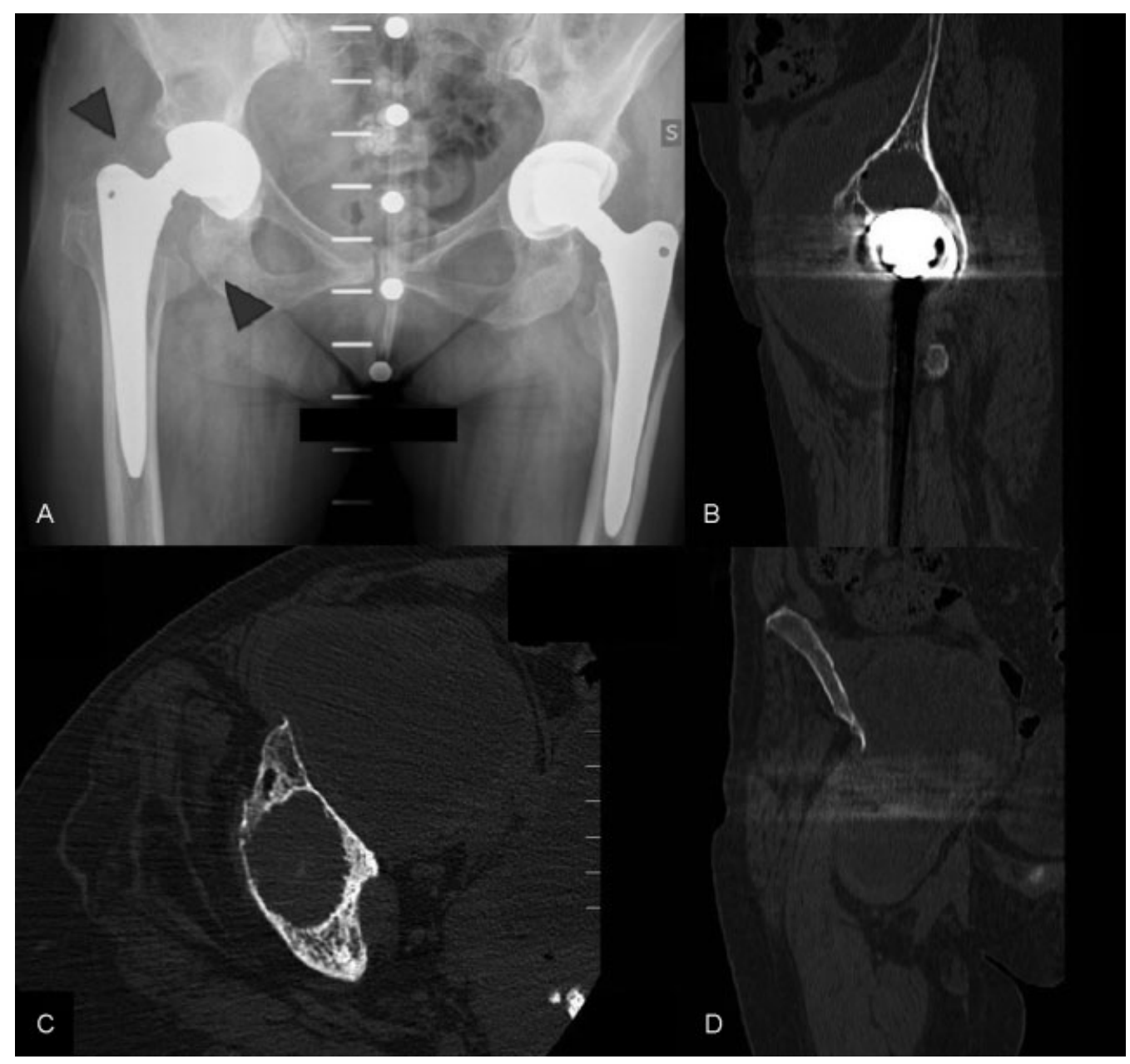

Fig. 1 (A) AP pelvis X-ray. A bubble sign is clearly visible around the acetabular cup. The arrows indicate the walls of the lesion. (B-D) CT scans showing a huge cystic pseudotumor, and bone resorption around the acetabulum and the greater trochanter. AP, anteroposterior; CT, computed tomography.

resonance imaging and computed tomography (CT) scan, a fluid mass (estimated $1,200 \mathrm{~mL}$ ) was detected, surrounding the hip anteriorly, occupying the anterior thigh, and the anterolateral aspect of the abdomen (-Fig. 1).

Part of the mass was reaching the anterior superior iliac spine anteriorly, thus facing the risk of damaging the pseudotumor capsule and spreading the liquid in the abdomen when positioning the patient in a lateral decubitus (by direct compression against the anterior support) with the risk of causing an acute peritonitis for metallosis' fluid spreading in the abdomen. The expert advice of abdominal and vascular surgeons was asked, and a mass evacuation was recommended.

A screening was performed for cobalt and chromium levels: blood values were within the reference value (RV); urine values were elevated, but below the acceptable value (AV) (blood cobalt $=0.20 \mu \mathrm{g} / \mathrm{L}$ [RV: 0.05-1.00 $\mu \mathrm{g} / \mathrm{L} ; \mathrm{AV}:<1.00 \mu \mathrm{g} / \mathrm{L}]$; blood chromium: $0.42 \mu \mathrm{g} / \mathrm{L}[\mathrm{RV}:<0.50 \mu \mathrm{g} / \mathrm{L} ; \mathrm{AV}:<17.00 \mu \mathrm{g} / \mathrm{L}]$; urine chromium: $0.65 \mu \mathrm{g} / \mathrm{L}$ [RV: 0.05-0.35 $\mu \mathrm{g} / \mathrm{L} ; \mathrm{AV}:<25.00 \mu \mathrm{g} / \mathrm{L}$; urine cobalt: $3.88 \mu \mathrm{g} / \mathrm{L}$ [RV: $0.2-2.00 \mu \mathrm{g} / \mathrm{L} ; \mathrm{AV}:<15.00 \mu \mathrm{g} / \mathrm{L}$ ]).

In September 2014, a two-step approach was arranged. The first step was the liquid evacuation with a catheter positioned under ultrasonographic guidance. During the procedure, $350 \mathrm{~mL}$ of black-stained fluid were drawn, and further
$500 \mathrm{~mL}$ were collected in the following 48 hours by vacuum aspiration. The procedure was performed in strict asepsis, and postprocedure antibiotical prophylaxis was adopted.

The microscopic analysis of the liquid showed an inflammatory liquid excluding infections. After 2 weeks a new CT scan was performed: the volume of the mass was reduced to $445 \mathrm{~mL}$ and was considered safe for surgery.

A posterolateral approach was adopted; when the joint was exposed a small amount of liquid was detected and aspirated. The greater trochanter showed a huge bone loss, but the stem was stable. Therefore it was left in place. On the acetabular side, the polyethylene inlay was fractured, and the metal back was mobilized and easily removed. Once the cup was removed, it was possible to aspirate $500 \mathrm{~mL}$ of liquid from a fistula over the anterior wall of the acetabulum. The bone resorption proximal to the cup and in the greater trochanter was filled with homologous bone ( 100 mL). A tantalum cup, reinforced with three screws, with ceramic insert was implanted, coupled with a ceramic head on the femoral side (Zimmer Inc., Warsaw, Indiana, United States) (-Fig. 2). During surgery three soft tissue samples were collected, the histological analysis reported: "inflammatory tissue without sign of infections." 


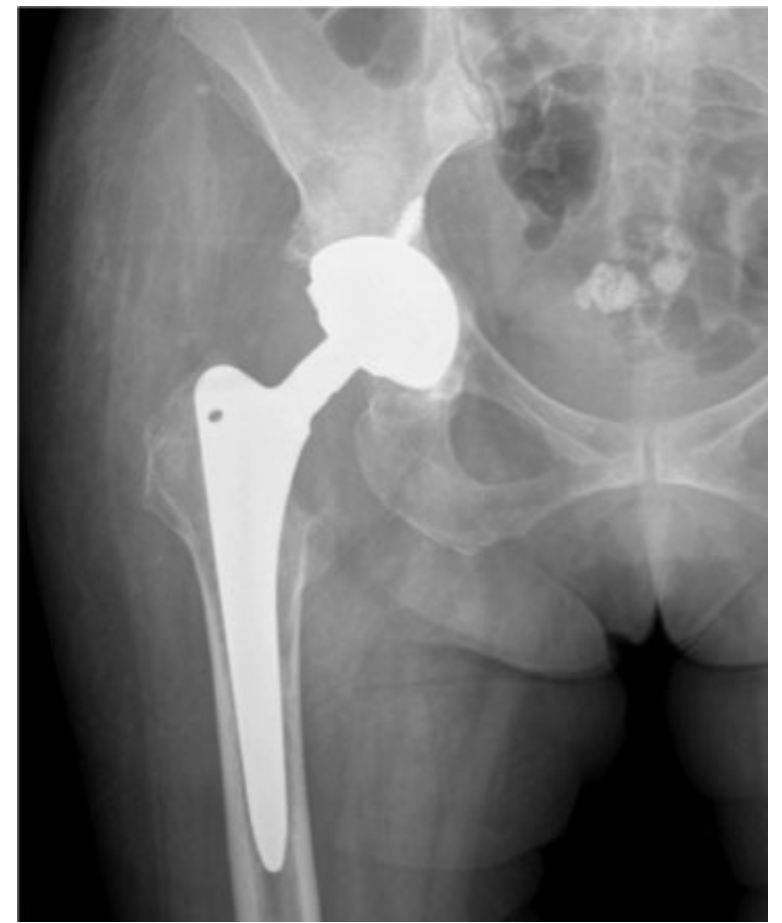

Fig. 2 Postoperative $X$-ray: a revision with a tantalum cup, reinforced with three screws, with ceramic on ceramic coupling + homologous bone filling of acetabular and trochanteric defects.

The toxicological screening was repeated 1 month after surgery and showed the following results: blood cobalt $=0.15 \mu \mathrm{g} / \mathrm{L}$; blood chromium $=0.42 \mu \mathrm{g} / \mathrm{L}$; urine chromium $=0.69 \mu \mathrm{g} / \mathrm{L}$; urine cobalt $=1.95 \mu \mathrm{g} / \mathrm{L}$.

The values on urine markedly decreased, according to a reduced metal ions release and urinary excretion. At a final CT scan, the remnants of the pseudotumor capsule were still detectable without fluid collection. The patient recovered painless full weight-bearing and returned to free activities of daily living within 2 months postoperatively, after more than 1 year she is still completely pain-free, and conducts a normal daily life.

\section{Discussion}

Pseudotumor treatment is still controversial and clear indications, or an algorithm is not available yet. The treatment of this pathology gives poor results with a high reintervention and complication rate. ${ }^{10,11}$ Patients who undergo a THA revision for pseudotumor, in almost 35\% of cases are revised again, and often experience the same level of pain and inability as before revision surgery. ${ }^{12}$ In literature, major complications are described to be up to $50 \%$, while in revisions for other indications the risk for complications accounts for not more than $14 \%^{12}$

Despite the lack of general consensus, there are certain trends for the management of pseudotumors. Symptomatic hips associated with pain and dysfunction, large pseudotumors, and elevated metal ion levels are likely to receive consideration for revision arthroplasty. Pseudotumors with- out associated pain, dysfunction, or elevated metal ion levels are more likely to receive ongoing surveillance without surgical intervention. Pseudotumors with serum metal ion levels $>20 \mu \mathrm{g} / \mathrm{L}$, with or without symptoms, are likely to receive serious consideration for revision arthroplasty. ${ }^{13}$

Liddle et al reported 39 cases of MoM THA revision, describing five types of failure, including fluid-filled pseudotumors, and solid mass pseudotumor. In the fluid-filled group, a plan for the possibility of muscle loss, including the need for muscle reconstruction (e.g., graft jacket) or captive cup is suggested. The help of a pelvic surgeon for full excision of intrapelvic mass may be required. With regard to this group, the solid mass group is affected by a higher risk of unsatisfactory results and has a higher incidence of further revision. ${ }^{14}$

With this case report, the authors outline the importance of approaching the problem of a huge pseudotumor more open-minded than the normal approach. Careful planning has to be performed, to evaluate dimensions, position, and relations to structures of the pseudotumor; patient positioning has to be considered too.

We proposed a two-stage approach. The first step was a minimally invasive procedure, with small risks, and turned out to be highly useful to define the diagnosis, to exclude other underlying pathologies such as infections or fistulae and to avoid complications. Histological and microbiological analyses were fundamental. The second step, a revision surgery, resulted then to be quite easy, simplified by the partial evacuation of the cyst. An easier revision surgery also reduced the surgical timing, thus lowering the risk of infections and bleeding.

\section{Conclusion}

We recommend a two-stage revision surgery in cases of huge cystic pseudotumor to avoid cyst rupture and facilitate the revision procedure.

\section{References}

1 Kwon Y-M, Ostlere SJ, McLardy-Smith P, Athanasou NA, Gill HS, Murray DW. "Asymptomatic" pseudotumors after metal-on-metal hip resurfacing arthroplasty: prevalence and metal ion study. J Arthroplasty 2011;26(04):511-518

2 Leigh W, O'Grady P, Lawson EM, Hung NA, Theis JC, Matheson J. Pelvic pseudotumor: an unusual presentation of an extra-articular granuloma in a well-fixed total hip arthroplasty. J Arthroplasty 2008;23(06):934-938

3 Pandit H, Glyn-Jones S, McLardy-Smith P. Pseudotumours associated with metal-on-metal hip resurfacings. J Bone Joint Surg $\mathrm{Br}$ 2008;90(07):847-851

4 Gruber FW, Böck A, Trattnig S, Lintner F, Ritschl P. Cystic lesion of the groin due to metallosis: a rare long-term complication of metal-on-metal total hip arthroplasty. J Arthroplasty 2007; 22(06):923-927

5 Clayton RA, Beggs I, Salter DM, Grant MH, Patton JT, Porter DE. Inflammatory pseudotumor associated with femoral nerve palsy following metal-on-metal resurfacing of the hip. A case report. J Bone Joint Surg Am 2008;90(09):1988-1993

6 Walsh AJ, Nikolaou VS, Antoniou J. Inflammatory pseudotumor complicating metal-on-highly cross-linked polyethylene total hip arthroplasty. J Arthroplasty 2012;27(02):324.e5324.e8 
7 Willert HG, Buchhorn GH, Fayyazi A, et al. Metal-on-metal bearings and hypersensitivity in patients with artificial hip joints. A clinical and histomorphological study. J Bone Joint Surg Am 2005;87(01):28-36

8 Cipriano CA, Issack PS, Beksac B, Della Valle AG, Sculco TP, Salvati EA. Metallosis after metal-on-polyethylene total hip arthroplasty. Am J Orthop (Belle Mead NJ) 2008;37(02):E18-E25

9 Su EP, Callander PW, Salvati EA. The bubble sign: a new radiographic sign in total hip arthroplasty. J Arthroplasty 2003;18(01): 110-112

10 van der Weegen W, Sijbesma T, Hoekstra HJ, Brakel K, Pilot P, Nelissen RG. Treatment of pseudotumors after metal-on-metal hip resurfacing based on magnetic resonance imaging, metal ion levels and symptoms. J Arthroplasty 2014;29(02):416-421
11 Williams DH, Greidanus NV, Masri BA, Duncan CP, Garbuz DS. Prevalence of pseudotumor in asymptomatic patients after metal-on-metal hip arthroplasty. J Bone Joint Surg Am 2011;93(23): 2164-2171

12 Grammatopoulos G, Pandit H, Kwon YM, et al. Hip resurfacings revised for inflammatory pseudotumour have a poor outcome. J Bone Joint Surg Br 2009;91(08):1019-1024

13 Davis DL, Morrison JJ. Hip arthroplasty pseudotumors: pathogenesis, imaging, and clinical decision making. J Clin Imaging Sci 2016;6:17. Doi: 10.4103/2156-7514.181493

14 Liddle AD, Satchithananda K, Henckel J, et al. Revision of metalon-metal hip arthroplasty in a tertiary center: a prospective study of 39 hips with between 1 and 4 years of follow-up. Acta Orthop 2013;84(03):237-245 